Таким образом, направления содержания методической работы в школе выявляются, прежде всего, из анализа уровня сформированности профессиональнопедагогической компетентности учителя, его образовательных «дефицитов», информационных запросов, а также составляющих его компетентности в области методики обучения (общей и частной), теории и практики воспитания с учётом современных явлений в обществе, психологии и педагогики, общей культуры учителя (этико-педагогической культуры), освоения новых технологий обучения, современных трендов и тенденций развития современного образования.

Актуализация современного содержания методической работы в аспекте новых трендов и тенденций развития образования предполагает их взаимосвязь, взаимодополнение, сбалансированность развития, что в свою очередь, обеспечит профессиональное развитие компетенций современного учителя.

1. Гордиенко И.В. Организация и управление методической работой в системе среднего профессионального образования : учеб.-методич. пособие / И.В. Гордиенко Ю.М. Мельник. Белгород: ОГАОУ ДПО «БелИРО», 2019. - 144 с

2. Десять трендов современного образования. [электронный ресурс] - Режим доступа: https://www.hse.ru/news/science/63841790.html

3. Маркова А.К. Психология профессионализма / А.К. Маркова. - М. : Знание, 2006. - 144 с

4. Мойсеюк Н.И. Педагогика : учеб. пособие для студентов высших учебных заведений / Н.И. Мойсеюк. - 5-е изд., доп. и перераб. - Киев : Саммит-книга, 2007. - 655 с.

5. Навыки XXI века: HP-Portal (HP - Сообщество и публикация). [электронный ресурс] - Режим доступа:https://hr-portal.ru/article/navyki-xxi-veka-novaya-realnost-v-obrazovanii

6. Тоффлер Ф. Футурошок / пер.с англ. / Ф. Тоффлер - СПб, 1997 -464 с.

7. Ушинский К.Д. Избранные труды. В 4 книгах. Книга 1. Проблемы педагогики /К.Д. Ушинский. - М.: Дрофа, 2005. - 640 с.

8. Черепанова Т.Б. Тренды и тенденции современной образовательной практики //Гуманитарные науки. 2019 №2 (23) C.139-141

\title{
Селиверстова Е.Н.
}

Новые грани в понимании сущности современного школьного обучения

Владимирский государственный университет (Россия, Владимир)

doi: 10.18411/scienceconf-11-2021-15

\section{Аннотация}

На основе анализа инновационной образовательной практики автором предпринята попытка выявления тенденций, отражающих обновление подходов к пониманию сущностных характеристик современного обучения в сравнении с классическими подходами. Внимание сосредоточено на раскрытии специфики познавательной деятельности обучающихся, реализующейся в современной практике обучения в учебном, игровом и проектном форматах. Это позволило сделать вывод о накоплении массива эмпирических данных, создающих основу для раскрытия новых сторон сущности обучения, отличных только от его учебно-познавательного предназначения.

Ключевые слова: современное обучение, сущность обучения, учебнопознавательная деятельность, игровая деятельность в обучении, проектная деятельность в обучении.

\section{Abstract}

Based on the analysis of innovative educational practices, the author attempts to identify trends that reflect the updating of approaches to understanding the modern education essential characteristics in comparison with classical approaches. Attention is focused on identifying the specifics of students' cognitive activity, which is implemented in modern 
teaching practice in educational, game and project formats. This allowed us to draw a conclusion about the accumulation of an array of empirical data that creates the basis for revealing new aspects of the education essence that differ from its educational and cognitive dominant.

Keywords: modern education, the essence of education, educational and cognitive activity, game activity in education, project activity in education.

Кардинальные изменения, характерные для инновационной практики современного школьного обучения, со всей очевидностью убеждают в необходимости углубления научных позиций педагогики в понимании сущности обучения. Классическое понимание обучения, акцентирующее внимание на учебнопознавательной ориентации деятельности обучающегося, которая придает познанию целенаправленный и осознанный характер, вступает в известное противоречие с тем, что в условиях современных инновационных образовательных практик все более характерным становится такой подход, когда познавательная деятельность школьников организуется не только в форме учебной деятельности. По-видимому, идет процесс накопления массива эмпирических данных о таких способах организации обучения, которые ориентированы на раскрытие новых сторон сущности обучения, отличных от его учебно-познавательного предназначения. Для того, чтобы понять направления этих трансформаций, обратимся к анализу специфики и образовательных возможностей тех видов деятельности обучающихся, включение в которые придает познавательной деятельности школьников обновленный формат, отличный от учебно-познавательных характеристик. В данном случае речь прежде всего идет об игровой деятельности и проектной деятельности, каждая из которых, вливаясь в обучение, открывает взгляд на его новые сущностные свойства.

В современной педагогике игра ребенка наряду с познанием рассматривается как важнейший способ освоения мира. Однако, в отличие от учебного познания, направленного на получение объективных, систематизированных, обоснованных и организованных в структуры научных знаний о природе, человеке и обществе, в игре школьник отражает реальность, трансформируя все увиденное и услышанное через свои собственные эмоции и субъективные переживания. Это обусловлено тем, что игровая деятельность представляет собой форму познания в условных/придуманных ситуациях, связанных с воспроизведением обучающимися действий и отношений взрослых, когда дети по собственному желанию принимают на себя определенные роли и подчиняются определенным правилам-ограничителям. Выступая средством самореализации и самовыражения ребенка, позволяющим ему выходить за пределы мира, смоделированного взрослыми, и выстраивать свой собственный мир, игра не предполагает выдвижения специальных познавательных задач, которые осознаются обучающимися как знак, сигнализирующий необходимость включения в познавательную деятельность. Именно поэтому Д.Б. Эльконин считал игру самостоятельным видом деятельности, в которой у ребенка происходит интенсивное развитие мотивационно-потребностной сферы, складывается и совершенствуется управление поведением, происходит эмоционально наполненное вхождение в жизнь взрослых, постижение общественных функций и смысла человеческого бытия, создавая богатейшие возможности для ориентации школьника во внешнем мире. Дети учатся в игре взаимодействовать с другими людьми, осваивать правила и способы взаимоотношений, обретают опыт взаимопонимания, учатся объяснять свои действия и намерения, согласовывать их с другими детьми. Поэтому закономерно, что действие в придуманной ситуации приводит к тому, что ребенок учится управлять не только познанием предметов или реальных обстоятельств, но и смысловым контекстом ситуации. Подчеркнем, что в игре ребенок приобретает опыт действия в ситуации, которая наряду с непосредственным переживанием требует также и познания, которое, 
однако, существенно отличается от познания в условиях учебной деятельности. Игра позволяет школьнику постигать новое качество отношения к миру, когда он видит вокруг себя не только многообразие форм проявления мира, но и начинает постигать смысл окружающей действительности, вырабатывая таким образом ценностносмысловое отношение к познанию мира.

Очевидно, включение обучающихся в познание посредством игровой деятельности приводит к возникновению особой познавательной позиции школьников. С одной стороны, познание в процессе обучения уже не может быть сведено к прежнему его пониманию, как только учебной деятельности, которая отличается отчетливым осознанием обучающимися осваиваемого содержания и используемых способов познания. Но, с другой стороны, такое познание не может быть полностью отождествлено и с игровой деятельностью, в которой на первый план выступают эмоции, переживания, стремления школьника удовлетворить свои интересы, самореализоваться и выразить себя, когда в ситуациях увлеченности игровым сюжетом собственно познавательный аспект, хотя и проявляется, но скорее всего не осознается ими как специальная, планируемая цель. Мы полагаем, что включение обучающихся в познание в формате игры, значительно трансформирующее классические представления о качественных характеристиках познавательной деятельности обучающихся, следует рассматривать как свидетельство происходящих сегодня качественных изменений в понимании сущности, целевых установок и способов организации обучения в целом. Показательно, что уже с середины XX века в зарубежной педагогике началось осознание подобных изменений на понятийном уровне и в научный оборот был введен новый термин «эдьютейнмент» [1;2; 3 и др.]. Поскольку в основе его лежат два английских слова - «education» - «обучение» и «entertainment» - «развлечение», то, можно сделать некоторые обобщающие выводы относительно новых свойств обучения: обучение строится на включении школьников в такую познавательную деятельность, которая сопровождается одновременным удовлетворением любопытства обучающихся, что, как утверждают психологи, способствует глубокому погружению в изучаемый материал. Происходящее при этом освоение серьезного учебного материала в эмоционально благоприятной для обучающихся атмосфере (в несерьезном тоне), позволяет снимать излишнее давление на психику и эмоциональное напряжение и тем самым способствует более активному протеканию психических познавательных процессов.

Сущностными проявлениями эдьютейнмента выступают такие его свойства, которые позволяют обнаружить новые смысловые характеристики обучения, не свойственные классическому пониманию. К ним целесообразно отнести неформальную обстановку и положительно окрашенную атмосферу занятий, призванную удовлетворить увлечения и интересы обучающихся, а также развлечь их; отсутствие строгих рамок и запретов, контроля со стороны педагога; возможность обучающихся активно общаться и обогащать друг друга знаниями; опору на индивидуальные темпы познания. Анализ исследований по проблематике эдьютеймента убеждает в том, что в отличие от традиционного понимания сущности обучения, основанного на доминанте учебно-познавательной, т.е. осознанной и целенаправленной познавательной деятельности, ключевым ядром эдьютейнмента является опора на бессознательные механизмы познания, когда обучающиеся, опираясь на свои актуальные интересы, предпочтения и субъективные способы понимания, получают возможность в свободной обстановке обсудить различные вопросы и получить для себя нужную информацию без четкой предварительной постановки познавательных задач.

Как видим, выявленные характеристики противоречат принципам классической дидактики (к примеру, принципу систематичности и последовательности и др.), а обучение, организованное в формате эдьютейнмента, не позволяет добиваться достижения планируемых результатов в освоении обучающимися знаний и способов 
действия. Вместе с тем важно, что несмотря на отсутствие учебно-познавательной доминанты, это обучение позволяет решать ряд образовательных задач, связанных с достижением личностных результатов обучения. В первую очередь речь идет об очень важной стороне - возможности каждому обучающемуся получить удовольствие от самого процесса познания, ощутить его значимость для жизни и сформировать ценностно-смысловое отношение к познанию.

Наряду с зарубежными поисками сходные по своей сути педагогические позиции, для которых характерным является отход от полной осознанности обучающимися своего процесса познания и его результатов, разрабатывает и ряд отечественных педагогов-исследователей. К примеру, Букатов В.М., который предложил инновационный подход к организации обучения, основанный на драмо/герменевтике [3], или Окунев А.А., который на своих уроках математики систематически использует сочинение школьниками сказок, сюжетом и героями которых выступают математические объекты, понятия и отношения [7].

Мы полагаем, что ценность игрового и развлекательного обучения более всего обусловлена необходимостью включения в контекст научного познания личностного опыта обучающихся, который, как известно, придает обучению не только целе-, но и ценностно ориентированный характер. Личностный опыт, основу которого составляют ценности, не может быть передан в готовом виде, а должен быть выстроен самой личностью в условиях свободного выбора содержания и способов познания, диалогического взаимодействия всех субъектов обучения, обмена разными, но равноправными мнениями, суждениями и оценками, что открывает путь к обретению обучающимися ценности познания и творчества, обеспечивает предпосылки для окультуривания используемых способов самоопределения в познании.

Наравне с игровой деятельностью не менее значимую роль в современном обучении начинает приобретать и проектная деятельность. По мнению исследователей [5; 6; 8 и др.], она представляет собой особый вид деятельности, имеющей ограничения во времени, направленной на создание заранее предполагаемого значимого для обучающихся продукта с ориентацией на обозначенные сроки и требования к его качеству. В проектной деятельности при непосредственной поддержке учителя обучающиеся оказываются в ситуации самостоятельной постановки конкретных задач, обеспечивающих получение необходимого продукта, отбора внутренних и внешних ресурсов в ходе разработки стратегии и тактики для достижения желаемых результатов. Подчеркнем, что для этой деятельности сущностной является не столько учебнопознавательная доминанта (нацеленность на познание нового как сверхзадачу), сколько метапредметные составляющие - опыт жизненной самоорганизации и саморегуляции в условиях разработки и реализации стратегий достижения личностно значимых для себя результатов, поскольку 1) проект посвящается проблеме, имеющей для обучающихся личностную значимость - теоретическую, практическую или познавательную, что, безусловно, влияет на развитие мотивации и создает надежные предпосылки для проявления избирательности школьников в процессе обучения; 2) результатом выполнения проекта выступает не просто что-то новое, а то, что отвечает потребностям и интересам конкретного школьника, обусловливая накопление опыта творческисозидательной деятельности обучающихся, повышая уровень их познавательной активности и тем самым укрепляя в их растущем сознании ценность творчества; 3) разработка стратегии и тактики выполнения проекта, основанная на выборе оптимальных для обучающегося способов деятельности и ресурсного сопровождения, обеспечивает постепенное формирование у школьников способов самоорганизации и саморегуляции в процессе осуществления различных видов деятельности, что является продуктивным в отношении накопления опыта жизненного самоопределения, самореализации и самосовершенствования. 
Проведенный анализ, выявляющий вектор трансформационных процессов, характерных для познавательной деятельности школьников в современном обучении, достаточно отчетливо демонстрирует тенденцию, состоящую в осознании того, что современное обучение обретает такие новые свойства («субстанциональное ядро»), без которых оно сегодня не может мыслиться как современное обучение. Речь идет о свойствах, которые нельзя игнорировать и изменять, поскольку они определяют все остальные характеристики современного обучения как дидактической системы, предъявляя соответствующие требования к содержанию, методам и формам организации обучения. В основе выделения этих сущностных свойств, без которых современное обучение перестает быть самим собой, лежит методология антропологического подхода в его современном (неклассическом) прочтении [9]. В соответствии с ним познание «предстает как процесс понимания, осмысления конструирования смыслов окружающих явлений и процессов человеком, установления их значимости для людей в зависимости от социокультурного контекста. ... В отличие от классической философии, для которой истина есть цель познания, в неклассической философии целью познания выступает решение постоянно возникающих в процессе человеческой деятельности проблем» [9, с. 77]. Отсюда, ясно, что обновленные ракурсы рассмотрения сущности обучения должны исходить из понимания того, что организуемое ученическое познание нуждается в разнообразии форматов, не сводящих его только к учебной деятельности, имеющей исключительно целевую ориентацию. В качестве необходимого и обязательного признается также доминанта ценностного формата познания. В частности, включение школьников в игровую и проектную деятельности приводит к тому, что осуществляемое познание мира перестает ограничиваться только учебными установками с приоритетом на целевое приобретение нового. Участвуя в игре и в выполнении проектов, обучающиеся начинают приобретать опыт самопознания - осознавать себя, свои идеалы, потребности и интересы, и на этой основе вырабатывать личностно значимую программу действий, занимать выработанную ими самостоятельно ценностную (а не только целевую) позицию в познании. Очевидно, такой подход позволяет рассматривать познание школьников в обучении в его широком культурном контексте, который предполагает осмысление познания как универсальной деятельности человека, пронизывающей все виды деятельности и составляющей основу жизнедеятельности человека в целом.

Как видим, современная неклассическая методология диктует целесообразность понимать сущность обучения как целенаправленного и систематического включения школьников в познание и самопознание, осуществляемые не только в традиционном формате учебной деятельности, но и в условиях других видов деятельности, составляющих контекст жизнедеятельности современного человека. Происходящее на этой основе расширение познавательных горизонтов обучения посредством реализации не только его целевых, но и в равной мере ценностных начал, позволит планировать и обеспечивать формирование у обучающихся кроме опыта научного познания, еще и столь же необходимого в современной жизни опыта познания как универсальной деятельности человека, составляющей основу жизненного самоопределения, самореализации и самосовершенствования как важнейших характеристик зрелой саморазвивающейся личности.

$$
* * *
$$

1. Богданова О.А. Эдбютейнмент как особый тип обучения // Вестник Московского городского педагогического университета. Серия: Информатика и информатизация образования. 2014. № 4(30). C.61-65.

2. Букатов В. М. Эдьютеймент: дидактические уроки игровых инноваций в образовании взрослых // Актуальные проблемы психологического знания. 2017. № 2. С. 20-26.

3. Букатов В.М., Ершова А.П. Нескучные уроки: Обстоятельное изложение игровых технологий обучения школьников: пособие для учителей физики, химии, математики, географии, биологии. Спб : Школьная лига, 2013. 240 с. 
4. Воровщиков С.Г. Специфика учебно-познавательной деятельности как разновидности учения школьников//Преподаватель ХХІ век. 2009. № 4. С. 16-27.

5. Зимняя И.А. Педагогическая психология: учебник для вузов. Изд. 2-е, доп., испр. и перераб. М.: ЛОГОС, 2000. 384 с.

6. Матяш Н.В. Инновационные педагогические технологии: Проектное обучение. 2-е изд., доп. М.: Академия, 2012. 160 c.

7. Окунев А.А. Спасибо за урок, дети. М.: Просвещение, 2010. 163 с.

8. Поливанова К.Н. Проектная деятельность школьников. 2-е изд. М.: Просвещение, 2011. 192 с.

9. Сергейчик Е.М. Философские основания антропологического подхода в постнеклассической науке // Вестник Северного (Арктического) федерального университета. Серия: Гуманитарные и социальные науки. 2018. № 3. С. 70-82.

\section{Торшина А.B. \\ Педагогический потенциал клубной деятельности подростков Оренбуржья: история и современность}

Новотроиџкий филиал ФГАОУ ВО «Наџиональный исследовательский технологический университет «МИСиС»

(Россия, Новотроиик)

doi: 10.18411/scienceconf-11-2021-16

\section{Аннотация}

В статье раскрывается педагогический потенциал клубной деятельности подростков Оренбуржья в 1930 - 1950-е годы для современной практики дополнительного образования, заключающиеся в образовательных, личностноориентированных и социально-педагогических позициях.

Ключевые слова: клубная деятельность подростков, Оренбуржье, дополнительное образование; образовательные, личностно-ориентированные, социально-педагогические возможности.

\section{Abstract}

The article reveals the pedagogical potential of the club activity of Orenburg teenagers in the 1930s - 1950s for the modern practice of additional education, consisting in educational, personality-oriented and socio-pedagogical positions.

Keywords: club activity of teenagers, Orenburg region, additional education; educational, personality-oriented, socio-pedagogical opportunities.

В настоящее время актуализируется потребность создания (реконструкции) культурно-досуговых организаций клубного типа, содействия развитию дополнительного образования и социализации детей, в том числе за счет увеличения количества действующих клубов патриотической, спортивной и волонтерской направленности, воссоздания и поддержки сети клубов (детско-взрослых, подростковых) по месту жительства.

Использование категории «потенциал» в педагогической теории и практике предполагает выявление его сущности, содержания и структуры. Под потенциалом в научной литературе понимают возможности. Возможности представляют собой средства, условия, обстоятельства, необходимые для осуществления чего-нибудь [1].

При выявлении педагогического потенциала клубной деятельности подростков Оренбуржья в 1930-1950-е годы для современной практики дополнительного образования мы основывались на положении о том, что историко-педагогическое знание выступает«гарантом качества современной образовательной системы России в период ее активной модернизации» (А.М. Аллагулов) [2].

Педагогический потенциал клубной деятельности подростков Оренбуржья в 1930 - 1950-е годы для современной практики дополнительного образования, 